\title{
Estudos experimentais em coelhos com plantas cianogênicas ${ }^{1}$
}

\author{
Marilene F. Brito ${ }^{2}$, Ticiana N. França ${ }^{3}$, Krishna D. Oliveira ${ }^{3}$ e Valiria D. Cerqueira ${ }^{3}$
}

ABSTRACT.- Brito M.F., França T.N., Oliveira K.D. \& Cerqueira V.D. 2000. [Experiments in rabbits with cyanogenic plants.] Estudos experimentais em coelhos com plantas cianogênicas. Pesquisa Veterinária Brasileira 20(2):65-70. Projeto Sanidade Animal Embrapa/UFRRJ, Km 47, Seropédica, RJ 23851-970, Brazil.

The dried leaves of Piptadenia macrocarpa Benth. [=Anadenanthera macrocarpa (Benth.) Brenan], Piptadenia viridiflora (Kunth.) Benth. and Holocalyx glaziovii Taub.[=Holocalyx balansae Micheli], all trees of the Leguminosae Mimosoideae family, were given orally to rabbits in single doses. In the case of $\mathrm{H}$. glaziovii, leaves were fed after being stored in two different ways.

In the first series of experiments, Piptadenia macrocarpa failed to poison rabbits although the leaves were collected when sprouting, the most toxic stage for cattle. The experiments were performed 4 to 6 months after the leaves had been collected and dried. In a second series of experiments, similar leaves were fed at monthly intervals after harvest. They were toxic for the first 5 months, but were innocuous after 6 months storage. In both series of experiments the leaves were dried in the shade and then kept in cotton sacks at room temperature. They always were milled at the occasion of the experiments. These experiments with rabbits confirm the results with cattle, in which severe poisoning was caused by leaves stored for 3 months but caused no ill effect after 4 months, even when fed in large amounts. Young leaves of $P$. viridiflora were lethal at $12 \mathrm{~g} / \mathrm{kg}, 12$ months after collection and drying. In a second experiment the lethal dose was only $6 \mathrm{~g} / \mathrm{kg}$ with leaves stored for only 2 months. These results show that the dried leaves of these species lose toxicity with time. Holocalyx glaziovii leaves were milled 6 weeks after collecting and dried and stored in sealed containers. They were fed in single doses to different rabbits at intervals during a whole year. Lethal doses were initially $0.75 \mathrm{~g} / \mathrm{kg}$ to $1.5 \mathrm{~g} / \mathrm{kg}$ but rose to $1.5 \mathrm{~g} / \mathrm{kg}$ to $3 \mathrm{~g} / \mathrm{kg}$ by the end of the year. In a second experiment, leaves stored in cotton sacks and milled just before feeding were compared with milled leaves stored in sealed glass containers. The plant material kept in cotton sacks had half the toxicity of the leaves stored for 2 months in sealed containers. After 10 to 12 months it was only a little less toxic than that stored in the sealed containers but there were no differences after 14 months.

The symptoms observed in the rabbits that were poisoned by the dried leaves of $P$. macrocarpa, $P$. viridiflora and $H$. glaziovii were neuromuscular. Post-mortem findings and histopathological findings were almost absent. On opening the stomach, a strong smell of bitter almonds was sometimes noticed. The degree of toxicity during the storage of the dried leaves of the three tested plants was generally well correlated with the picrate test for cyanide.

INDEX TERMS: Poisonous plants, experimental poisoning, hydrocyanic poisoning, Piptadenia macrocarpa, Piptadenia anadenanthera, Piptadenia viridiflora, Holocalyx glaziovii, Holocalyx balansae, rabbits.

\footnotetext{
${ }^{1}$ Aceito para publicação em 26 de fevereiro de 1999.

${ }^{2}$ Depto Epidemiologia e Saúde Pública, Setor de Anatomia Patológica, Universidade Federal Rural do Rio de Janeiro (UFRRJ), 23835-000 Seropédica, RJ.

${ }^{3}$ Aluna da Pós-Graduação em Medicina Veterinária, área de concentração em Patologia Veterinária, UFRRJ.
}

RESUMO.- A administração por via oral das folhas dessecadas de Piptadenia macrocarpa (Benth. [=Anadenanthera macrocarpa (Benth.) Brenan], Piptadenia viridiflora (Kunth.) Benth. e Holocalyx glaziovii Taub. [=Holocalyx balansae Micheli], plantas cianogênicas da família Leguminosae Mimosoideae, revelou a sensibilidade do coelho à elas, caracterizando-se a 
intoxicação por sintomatologia de natureza neuromuscular. A dose letal de $P$. macrocarpa foi de $6 \mathrm{~g} / \mathrm{kg}$ para a brotação dessecada, até 5 meses após sua coleta; 6 meses depois da coleta a planta havia perdido a toxidez. A dose letal de $P$. viridiflora foi também de $6 \mathrm{~g} / \mathrm{kg}$ para a brotação dessecada, coletada dois meses antes dos experimentos; 10 meses após a coleta a planta havia perdido metade da toxidez. Com $H$. glaziovii foram realizadas duas séries experimentais; estabeleceu-se a dose letal entre 0,75 e $1,5 \mathrm{~g} / \mathrm{kg}$ com a planta coletada 2 meses antes, também com perda aproximada de metade da toxidez no período de 12 meses. $O$ experimentos indicam, que H. glaziovii, moída logo após a coleta e armazenada em vidros fechados com tampa plástica, conserva melhor a toxidez nos primeiros meses do que a planta guardada em sacos de algodão, porém, ao final de um ano, essa diferença deixa de existir. A toxidez das folhas dessecadas foi proporcional à intensidade das reações das mesmas ao teste do papel picro-sódico, com raras exceções

TERMOS DE INDEXAÇÃO: Plantas tóxicas, intoxicação experimental, intoxicação cianídrica, Piptadenia macrocarpa, Anadenanthera macrocarpa, Piptadenia viridiflora, Holocalxy glaziovii, Holocalyx balansae, coelhos.

\section{INTRODUÇÃO}

Estudos experimentais em bovinos evidenciaram que Piptadenia macrocarpa, Piptadenia viridiflora e Holocalxy glaziovii induzem a intoxicação cianídrica e que, ao contrário de Manihot glaziovii, ainda mantêm sua toxidez após o processo de dessecagem (Tokarnia et al. 1994, 1999). Verificou-se ainda, nesses estudos, que todas as quatro plantas apresentam resultados positivos na prova do papel picro-sódico e também que animais gravemente intoxicados por essas plantas, se recuperam prontamente pela administração de hipossulfito de sódio, fatos que as caracterizam, definitivamente, como plantas cianogênicas.

A presente série experimental foi realizada com a finalidade de verificar se o coelho é sensível à ação dessas plantas, com vistas a futuros experimentos, como por exemplo, sobre a intoxicação crônica e o efeito bocígeno dessas plantas. Experimentos adicionais foram efetuados com $\mathrm{H}$. glaziovii no sentido de se verificar se o tipo de armazenamento influencia a conservação da toxidez de uma dessas plantas $(H$. glaziovii).

\section{MATERIAL E MÉTODOS}

As folhas moídas das três leguminosas foram administradas aos coelhos em doses únicas, previamente determinadas, por meio de um funil adaptado a uma sonda, método descrito anteriormente (Döbereiner et al. 1976), mas simplificado pela utilização de um funil simples. Os coelhos eram mantidos em gaiolas individuais e recebiam ração comercial e água.

Após a administração da planta, os animais eram observados durante a maior parte do dia. Nos casos de morte, fazia-se a necropsia com coleta de material para exames histopatológicos. Esse material era fixado em formol a $10 \%$, incluído em parafina e corado pela hematoxilina-eosina (HE).
No mesmo dia ou em dia próximo ao dos experimentos, as plantas, previamente umedecidas com água, eram submetidas ao teste do papel picro-sódico.

Dados específicos sobre a coleta e conservação (armazenagem) de cada uma das três plantas são fornecidos a seguir.

Piptadenia macrocarpa. As folhas (na fase de brotação) foram coletadas em 18.10.97, para os experimento da primeira série, e em 10.8.99, para os experimentos da segunda série, no Instituto de Zootecnia da UFRRJ, município de Seropédica, RJ, de árvores cultivadas a partir de sementes procedentes do Piauí (mun. Pimenteiras). As folhas foram então dessecadas à sombra, guardadas em sacos de algodão à temperatura ambiente e moídas em moinho martelo Wiley com malha 60 , poucos dias antes dos experimentose, guardadas em vidros fechados com tampa plástica e mantidos à temperatura ambiente.

Piptadenia viridiflora. As folhas (brotos) coletadas no município de Wanderley, Bahia, foram submetidas ao mesmo procedimento acima mencionado. Na primeira série de experimentos a planta foi coletada em 16.03.97 e moída em 14.06.97, para a segunda série foi coletada em 01.06.1998 e moída em 17.07.98

Holocalyx glaziovii. As folhas foram coletadas em 28.04.97 no Sítio Porangaba, município de Itaguaí, RJ, de árvores cultivadas a partir de mudas procedentes do município de Campinas, SP e submetidas ao mesmo procedimento. Parte da planta foi moída em 14.06.97 e guardada em vidros fechados com tampa plástica e mantida à temperatura ambiente. Outra parte, coletada em 28.04.97, foi guardada em sacos de algodão, à temperatura ambiente $\mathrm{e}$ somente moída imediatamente antes da administração aos coelhos. As administrações da planta, armazenada das duas maneiras diferentes, eram feitas à intervalos pre-determinados e sempre nos mesmos dias.

A relação planta dessecada/planta fresca foi para $P$. macrocarpa $=5,7 / 10$, para $P$. viridiflora $=5 / 10$ e para $H$. glaziovii $=5 / 10$.

\section{RESULTADOS}

Piptadenia macrocarpa (Quadros 1 e 2)

Na primeira série de experimentos não foi possível intoxicar os coelhos; nem a dose de $12 \mathrm{~g} / \mathrm{kg}$ das folhas dessecadas de $P$. macrocarpa causou quaisquer sintomas de intoxicação. Na segunda série de experimentos a dose letal foi $6 \mathrm{~g} / \mathrm{kg}$ da folha dessecada; só um coelho morreu com a dose de $3 \mathrm{~g} / \mathrm{kg}$. $O$ início dos sintomas ocorreu entre 7 e 86 minutos após a administração da planta. Os sintomas observados em todos os animais foram bastante uniformes: taquipnéia/dispnéia (5/6) , cabeça pendente meio inclinada até apoiar o queixo no piso da gaiola $(5 / 6)$, opistótono $(3 / 6)$, tremores $(3 / 6)$, movimentos desordenados/desequilíbrio (5/6), decúbito lateral (3/6), movimentos respiratórios cada vez mais espaçados e superficiais (5/6) e movimentos de pedalagem (1/6). Os achados de necropsia foram negativos. As alterações histológicas se resumiram em leve (2/6) ou moderada (2/6) congestão do baço, leve congestão nos rins (6/6), leve congestão pulmonar (1/6), áreas com hemorragias intra-alveolares no pulmão $(2 / 6)$, leve congestão hepática (2/6), e leve a moderada vacuo-lização difusa das células hepáticas, mais acentuada no centro $(1 / 6)$, mais acentuada na zona intermediária do lóbulo (2/6). 
Quadro 1. Experimentos com as folhas dessecadas de Piptadenia macrocarpa em coelhos. Folhas coletadas em 28.10.97 e guardadas em sacos de algodão ( $1^{\mathrm{a}}$ série)

\begin{tabular}{|c|c|c|c|c|c|c|c|}
\hline Coelho nş & $\begin{array}{l}\text { Peso } \\
\mathrm{g}\end{array}$ & $\begin{array}{l}\text { Data do ex- } \\
\text { perimento }\end{array}$ & $\begin{array}{l}\text { Data em } \\
\text { que a planta } \\
\text { foi moída }\end{array}$ & $\begin{array}{c}\text { Dose da } \\
\text { planta } \\
\text { dessecada } \\
\text { g/kg }\end{array}$ & Desfecho & $\begin{array}{l}\text { Início dos } \\
\text { sintomas } \\
\text { após admi- } \\
\text { nistração }\end{array}$ & $\begin{array}{l}\text { Evolução da } \\
\text { intoxicação }\end{array}$ \\
\hline 1321 & 2850 & 09.03.98 & 02.03 .98 & 5,7 & Sem sintomas & - & - \\
\hline 1331 & 2930 & 23.03 .98 & 02.03 .98 & 9,5 & Sem sintomas & - & - \\
\hline 1338 & 3820 & 22.04 .98 & 20.04 .98 & 12,0 & Sem sintomas & - & - \\
\hline
\end{tabular}

Quadro 2. Experimentos com as folhas dessecadas de Piptadenia macrocarpa em coelhos. Folhas coletadas em 30.8 .99 e guardadas em sacos de algodão ( $2^{\mathrm{a}}$ série)

\begin{tabular}{|c|c|c|c|c|c|c|c|}
\hline $\begin{array}{l}\text { Coelho nş } \\
\text { (Reg. SAP) }\end{array}$ & $\begin{array}{l}\text { Peso } \\
\mathrm{g}\end{array}$ & $\begin{array}{l}\text { Data do ex- } \\
\text { perimento }\end{array}$ & $\begin{array}{l}\text { Data em } \\
\text { que a planta } \\
\text { foi moída }\end{array}$ & $\begin{array}{c}\text { Dose da } \\
\text { planta } \\
\text { dessecada } \\
\text { g/kg }\end{array}$ & Desfecho & $\begin{array}{l}\text { Início dos } \\
\text { sintomas } \\
\text { após admi- } \\
\text { nistração }\end{array}$ & $\begin{array}{l}\text { Evolução da } \\
\text { intoxicação }\end{array}$ \\
\hline 1382 & 3100 & 07.10 .99 & 04.10 .99 & 3,0 & Sem sintoma & - & - \\
\hline 1381 (28909) & 3040 & 07.10 .99 & 04.10 .99 & 6,0 & Morreu & $53 \mathrm{~min}$ & $1 \mathrm{~h} 24 \mathrm{~min}$ \\
\hline 1379 & 3400 & 03.11 .99 & 01.11 .99 & 3,0 & Sem sintomas & - & - \\
\hline $1378(28921)$ & 3450 & 03.11 .99 & 01.11 .99 & 6,0 & Morreu & $105 \mathrm{~min}$ & $54 \mathrm{~min}$ \\
\hline 1373 & 3560 & 02.12 .99 & 29.11.99 & 1,5 & Sem sintomas & - & - \\
\hline $1380(28961)$ & 3760 & 02.12 .99 & 29.11 .99 & 3,0 & Morreu & $27 \mathrm{~min}$ & $4 \mathrm{~h} 15 \mathrm{~min}$ \\
\hline $1372(28960)$ & 3640 & 02.12 .99 & 29.11 .99 & 6,0 & Morreu & $36 \mathrm{~min}$ & $1 \mathrm{~h} 26 \mathrm{~min}$ \\
\hline 1383 & 2680 & 04.01 .00 & 03.01 .00 & 3,0 & Sem sintomas & - & - \\
\hline 1377 (28974) & 2740 & 04.01 .00 & 03.01 .00 & 6,0 & Morreu & $25 \mathrm{~min}$ & $7 \mathrm{~min}$ \\
\hline 1384 & 3620 & 07.02 .00 & 04.02 .00 & 3,0 & Sem sintomas & - & - \\
\hline 1385 (29004) & 3120 & 07.02 .00 & 04.02 .00 & 6,0 & Morreu & $35 \mathrm{~min}$ & $58 \mathrm{~min}$ \\
\hline 1376 & 3020 & 09.03 .00 & 06.03 .00 & 3,0 & Sem sintomas & - & - \\
\hline 1374 & 2950 & 09.03 .00 & 06.03 .00 & 6,0 & Sem sintomas & - & - \\
\hline 1390 & 2820 & 09.03 .00 & 06.03 .00 & 6,0 & Sem sintomas & - & - \\
\hline 1371 & 3280 & 09.03 .00 & 06.03 .00 & 12,0 & Sem sintomas & - & - \\
\hline 1387 & 2680 & 09.03 .00 & 06.03 .00 & 12,0 & Sem sintomas & - & - \\
\hline
\end{tabular}

Quadro 3. Experimentos em coelhos com as folhas dessecadas de Piptadenia viridiflora. Folhas coletadas em 16.03.97 e moídas em 14.06 .97 ( $1^{\mathrm{a}}$ série)

\begin{tabular}{|c|c|c|c|c|c|c|c|}
\hline $\begin{array}{l}\text { Coelho nş } \\
\text { (Reg. SAP) }\end{array}$ & $\begin{array}{c}\text { Peso } \\
\mathrm{g}\end{array}$ & $\begin{array}{l}\text { Data do ex- } \\
\text { perimento }\end{array}$ & $\begin{array}{l}\text { Data em } \\
\text { que a planta } \\
\text { foi moída }\end{array}$ & $\begin{array}{l}\text { Dose da } \\
\text { planta } \\
\text { dessecada } \\
\mathrm{g} / \mathrm{kg}\end{array}$ & Desfecho & $\begin{array}{l}\text { Início dos } \\
\text { sintomas } \\
\text { após admi- } \\
\text { nistração }\end{array}$ & $\begin{array}{l}\text { Evolução da } \\
\text { intoxicação }\end{array}$ \\
\hline 1299 & 3220 & 14.06 .97 & 14.06 .97 & 2,5 & Sem sintomas & & \\
\hline 1294 & 3740 & 14.06 .97 & 14.06 .97 & 5,0 & Sem sintomas & & \\
\hline 1323 & 2970 & 09.03 .98 & 14.06 .97 & 5,7 & Sem sintomas & & \\
\hline 1333 (28486) & 2990 & 23.03 .98 & 14.06 .97 & 12,0 & Morreu & $8 \mathrm{~min}$ & $94 \mathrm{~min}$ \\
\hline 1337 & 3600 & 22.04 .98 & 14.06 .97 & 8,5 & Sem sintomas & & \\
\hline 1340 & 3750 & 07.05 .98 & 14.06.97 & 10,0 & Sem sintomas & & \\
\hline
\end{tabular}

Piptadenia viridiflora (Quadros 3 e 4)

Na primeira série de experimentos a dose letal foi $12 \mathrm{~g} /$ $\mathrm{kg}$ da folha dessecada; na segunda série doses a partir de 6 $\mathrm{g} / \mathrm{kg}$ causaram a morte dos coelhos. $\mathrm{O}$ início dos sintomas ocorreu entre 8 e 62 minutos após a administração da planta ou após a última administração da planta (nos experimentos com doses acima de $6 \mathrm{~g} / \mathrm{kg}$, a planta era dada em 2 administrações, com intervalo de 2 a 3 horas entre elas). Os sintomas observados em todos os animais foram bastante uniformes: taquipnéia/dispnéia $(3 / 4)^{4}$, cabeça pendente meio inclinada

\footnotetext{
${ }^{4}$ 3/4 significa que 3 entre 4 animais mostraram esta sintomatologia ou lesão.
}

até apoiar o queixo no piso da gaiola (2/4), opistótono (1/4), tremores da cabeça(1/4), movimentos desordenados $(4 / 4)$, decúbito lateral (4/4), movimentos respiratórios cada vez mais espaçados (3/4) e movimentos de pedalagem (3/4). Os achados de necropsia foram negativos. À abertura do estômago, havia cheiro de amêndoas amargas (2/4). As alterações histológicas se resumiram em moderada congestão do baço (4/4), leve congestão no rim (4/4), leve congestão no pulmão (2/4) e moderada congestão no fígado (1/4).

Holocalyx glaziovii (Quadros 5 e 6)

A dose letal, independentemente do prazo em que foram realizados os experimentos após a coleta das folhas, da épo- 
Quadro 4. Experimentos com as folhas dessecadas de Piptadenia viridiflora em coelhos. Folhas coletadas em 01.06.98 e moídas em 17.07.98 (2a série)

\begin{tabular}{cccccccc}
\hline $\begin{array}{c}\text { Coelho } \mathbf{n}^{\circ} \\
\text { (Reg. SAP) }\end{array}$ & $\begin{array}{c}\text { Peso } \\
\mathrm{g}\end{array}$ & $\begin{array}{c}\text { Data do ex- } \\
\text { perimento }\end{array}$ & $\begin{array}{c}\text { Data em } \\
\text { que a planta } \\
\text { foi moída }\end{array}$ & $\begin{array}{c}\text { Dose da } \\
\text { planta } \\
\text { dessecada } \\
\mathrm{g} / \mathrm{kg}\end{array}$ & $\begin{array}{c}\text { Desfecho } \\
\text { Início dos } \\
\text { sintomas } \\
\text { após admi- } \\
\text { nistração }\end{array}$ & $\begin{array}{c}\text { Evolução da } \\
\text { intoxicação }\end{array}$ \\
\hline 1336 & 3640 & 20.07 .98 & 17.07 .98 & 5,0 & Sem sintomas & - \\
$1342(28561)$ & 2940 & 20.07 .98 & 17.07 .98 & 10,0 & Morreu & $30 \mathrm{~min}$ & $11 \mathrm{~min}$ \\
$1341(28562)$ & 3380 & 21.07 .98 & 17.07 .98 & 6,0 & Morreu & $62 \mathrm{~min}$ & $2 \mathrm{~h} 07 \mathrm{~min}$ \\
$1343(28563)$ & 3520 & 21.07 .98 & 17.07 .98 & 8,0 & Morreu & $49 \mathrm{~min}$ & $1 \mathrm{~h} 23 \mathrm{~min}$
\end{tabular}

Quadro 5. Experimentos em coelhos com as folhas dessecadas de Holocalyx glaziovii. Folhas coletadas em 28.04.97, moídas em 14.06.97 e guardadas em vidros fechados com tampa plástica ( $1^{\mathrm{a}}$ série)

\begin{tabular}{|c|c|c|c|c|c|c|c|}
\hline $\begin{array}{l}\text { Coelho no } \\
\text { (Reg. SAP) }\end{array}$ & $\begin{array}{l}\text { Peso } \\
\mathrm{g}\end{array}$ & $\begin{array}{l}\text { Data do ex- } \\
\text { perimento }\end{array}$ & $\begin{array}{c}\text { Data em } \\
\text { que a planta } \\
\text { foi moída }\end{array}$ & $\begin{array}{c}\text { Dose da } \\
\text { planta } \\
\text { dessecada } \\
\text { g/kg }\end{array}$ & Desfecho & $\begin{array}{l}\text { Início dos } \\
\text { sintomas } \\
\text { após admi- } \\
\text { nistração }\end{array}$ & $\begin{array}{l}\text { Evolução da } \\
\text { intoxicação }\end{array}$ \\
\hline 1302 & 3100 & 14.06 .97 & 14.06 .97 & 0,375 & Sem sintomas & - & - \\
\hline 1307 & 3180 & 18.06 .97 & 14.06 .97 & 0,375 & Sem sintomas & - & - \\
\hline 1301 & 3420 & 14.06 .97 & 14.06 .97 & 0,75 & $\begin{array}{l}\text { Adoeceu gravemente, } \\
\text { recuperou se }\end{array}$ & $10 \mathrm{~min}$ & $8 \mathrm{~h} 17 \mathrm{~min}$ \\
\hline $1308(28367)$ & 3800 & 18.06 .97 & 14.06 .97 & 0,75 & Morreu & $5 \mathrm{~min}$ & $3 \mathrm{~h} 55 \mathrm{~min}$ \\
\hline 1295(28363) & 4020 & 14.06 .97 & 14.06 .97 & 1,5 & Morreu & $3 \mathrm{~min}$ & $12 \mathrm{~min}$ \\
\hline $1303(28378)$ & 3720 & 09.07.97 & 14.06 .97 & 1,5 & Morreu & $9 \mathrm{~min}$ & $37 \mathrm{~min}$ \\
\hline 1324 & 2800 & 03.03 .98 & 14.06 .97 & 1,5 & Sem sintomas & - & - \\
\hline $1318(28482)$ & 2750 & 09.03 .98 & 14.06 .97 & 3,0 & Morreu & $10 \mathrm{~min}$ & $9 \mathrm{~min}$ \\
\hline $1328(28485)$ & 2650 & 16.03 .98 & 14.06 .97 & 1,5 & Morreu & $14 \mathrm{~min}$ & 1h08min \\
\hline 1335 & 2730 & 23.03 .98 & 14.06 .97 & 1,5 & Sem sintomas & - & - \\
\hline 1332(28494) & 3180 & 22.04 .98 & 14.06 .97 & 1,5 & Morreu & $?$ & $10 \mathrm{~h} 26 \mathrm{~min}$ \\
\hline 1341 & 2700 & 07.05 .98 & 14.06 .97 & 1,5 & Sem sintomas & - & - \\
\hline 1344(28522) & 3180 & 01.06 .98 & 14.06 .97 & 3,0 & Morreu & $7 \mathrm{~min}$ & $21 \mathrm{~min}$ \\
\hline
\end{tabular}

Quadro 6. Experimentos com as folhas dessecadas de Holocalyx glaziovii em coelhos. Folhas coletadas em 28.04.97 e guardadas em sacos de algodão (2Ş série)

\begin{tabular}{|c|c|c|c|c|c|c|c|}
\hline $\begin{array}{l}\text { Coelho } n^{\circ} \\
\text { (Reg. SAP) }\end{array}$ & $\begin{array}{c}\text { Peso } \\
\mathrm{g}\end{array}$ & $\begin{array}{l}\text { Data do ex- } \\
\text { perimento }\end{array}$ & $\begin{array}{l}\text { Data em } \\
\text { que a planta } \\
\text { foi moída }\end{array}$ & $\begin{array}{c}\text { Dose da } \\
\text { planta } \\
\text { dessecada } \\
\text { g/kg }\end{array}$ & Desfecho & $\begin{array}{l}\text { Início dos } \\
\text { sintomas } \\
\text { após admi- } \\
\text { nistração }\end{array}$ & $\begin{array}{l}\text { Evolução da } \\
\text { intoxicação }\end{array}$ \\
\hline 1310 & 3025 & 06.07 .97 & 06.07 .97 & 1,5 & Sem sintomas & - & - \\
\hline 1311(28377) & 3620 & 06.07 .97 & 06.07 .97 & 3,0 & Morreu & $9 \mathrm{~min}$ & $8 \mathrm{~min}$ \\
\hline 1329 & 2745 & 03.03 .98 & 02.03 .98 & 1,5 & Sem sintomas & - & - \\
\hline 1320 & 2660 & 09.03 .98 & 02.03 .98 & 3,0 & Leves sintomas & $28 \mathrm{~min}$ & $57 \mathrm{~min}$ \\
\hline 1322(28483) & 2740 & 16.03 .98 & 02.03 .98 & 3,0 & Morreu & $18 \mathrm{~min}$ & $01 \mathrm{~h} 07 \mathrm{~min}$ \\
\hline 1336 & 2700 & 23.03 .98 & 02.03 .98 & 3,0 & Sem sintomas & - & - \\
\hline 1334 & 3480 & 22.04 .98 & 02.03 .98 & 3,0 & Sem sintomas & - & - \\
\hline 1339(28498) & 3020 & 07.05 .98 & 06.05 .98 & 3,0 & Morreu & $4 \mathrm{~min}$ & $10 \mathrm{~min}$ \\
\hline 1345(28523) & 3480 & 01.06 .98 & 06.05 .98 & 3,0 & Morreu & $8 \mathrm{~min}$ & $25 \mathrm{~min}$ \\
\hline
\end{tabular}

ca da moagem das folhas e da maneira do seu armazenamento, variou de 0,75 a $3,0 \mathrm{~g} / \mathrm{kg}$. A menor dose que causou a morte foi de $0,75 \mathrm{~g} / \mathrm{kg} \mathrm{(1/2)}$ e a maior que não causou a morte foi de $3,0 \mathrm{~g} / \mathrm{kg}$ (3 de 9 coelhos não morreram). 0 início dos sintomas ocorreu, nos casos letais, entre 3 e 18 minutos após a administração da planta, e a evolução foi de 8 minutos a 10h26min, mas a maioria foi dentro de uma hora (7/11).

A sintomatologia, bastante uniforme, caracterizou-se por taquipnéia e dispnéia (10/11), cabeça inclinada para o lado (8/11), opistótono (7/11), tremores generalizados (5/11), movimentos desordenados/instabilidade/o animal debatendo-se (8/11), decúbito lateral (10/11), respiração espaçada (lenta) (8/11), movimentos de pedalagem (6/11). - À necropsia percebeu-se apenas, à abertura do estômago, forte cheiro de amêndoas amargas (4/11). As alterações histológicas se resumiram em leve (4/11), moderada (3/11) ou acentuada (2/ 
Quadro 7. Reações ao teste do papel picro-sódico das folhas dessecadas de Piptadenia macrocarpa

\begin{tabular}{|c|c|c|c|c|}
\hline $\begin{array}{l}\text { Prazo em } \\
\text { minutos }\end{array}$ & $\begin{array}{c}\text { Coletada em } 28.10 .97 \\
\text { Moída em } 2.3 .98 \\
\text { Testada em } 5.3 .98 \\
\text { (Coelhos } 1321,1331,1338 \text { ) }\end{array}$ & $\begin{array}{c}\text { Coletada em } 30.8 .99 \\
\text { Moída em } 4.10 .99 \\
\text { Testada em } 7.10 .99 \\
(\text { Coelhos } 1382,1381)\end{array}$ & $\begin{array}{c}\text { Coletada em 30.8.99 } \\
\text { Moída em 1.11.99 } \\
\text { Testada em 3.11.99 } \\
\text { (Coelhos 1379, 13780) }\end{array}$ & $\begin{array}{c}\text { Coletada em } 30.8 .99 \\
\text { Moída em 29.11.99 } \\
\text { Testada em 2.12.99 } \\
\text { (Coelhos } 1373,1380,1372)\end{array}$ \\
\hline 15 & - & $(+)$ & $(+)$ & - \\
\hline 20 & & & & \\
\hline 30 & & + & + & + \\
\hline 45 & $(+)$ & $+(+)$ & ++ & $+(+)$ \\
\hline 60 & + & ++ & +++ & $++(+)$ \\
\hline 70 & & & & +++ \\
\hline 80 & & +++ & & \\
\hline $\begin{array}{l}\text { Prazo em } \\
\text { minutos }\end{array}$ & $\begin{array}{c}\text { Coletada em 28.10.97 } \\
\text { Moída em 3.1.00 } \\
\text { Testada em } 4.1 .00 \\
\text { (Coelhos } 1383,1377 \text { ) }\end{array}$ & $\begin{array}{c}\text { Coletada em 30.8.99 } \\
\text { Moída em 4.2.00 } \\
\text { Testada em 7.2.00 } \\
\text { (Coelhos 13484, 1385) }\end{array}$ & $\begin{array}{c}\text { Coletada em 30.8.99 } \\
\text { Moída em 6.3.00 } \\
\text { Testada em 9.3.00 } \\
\text { (Coelhos } 1376,1374, \\
1390,1371,1387) \\
\end{array}$ & \\
\hline 15 & - & & & \\
\hline 20 & $(+)$ & ++ & + & \\
\hline 30 & + & +++ & ++ & \\
\hline 45 & ++ & & $++(+)$ & \\
\hline 60 & +++ & & +++ & \\
\hline
\end{tabular}

Quadro 8. Reações ao teste do papel picro-sódico das folhas dessecadas de Piptadenia viridiflora

\begin{tabular}{|c|c|c|c|c|}
\hline $\begin{array}{l}\text { Prazo em } \\
\text { minutos }\end{array}$ & $\begin{array}{l}\text { Coletada em } 16.3 .97 \\
\text { Moída em } 14.6 .97 \\
\text { Testada em } 9.3 .98 \\
\text { (Coelhos } 1323,1333)\end{array}$ & $\begin{array}{l}\text { Coletada em 16.3.97 } \\
\text { Moída em 14.6.97 } \\
\text { Testada em 24.4.98 } \\
\text { (Coelho 1337) }\end{array}$ & $\begin{array}{l}\text { Coletada em } 16.3 .97 \\
\text { Moída em } 14.6 .97 \\
\text { Testada em 7.5.98 } \\
\text { (Coelho 1340) }\end{array}$ & $\begin{array}{c}\text { Coletada em 1.6.98 } \\
\text { Moída em 17.7.98 } \\
\text { Testada em } 22.7 .98 \\
\text { (Coelhos } 1336,1342,1341,1343)\end{array}$ \\
\hline 20 & & & - & $(+)$ \\
\hline 30 & & - & & $+(+)$ \\
\hline 45 & & & & +++ \\
\hline 60 & $(+)$ & $(+)$ & $(+)$ & \\
\hline 90 & + & + & + & \\
\hline $2 \mathrm{~h}$ & & & $+(+)$ & \\
\hline $3 \mathrm{~h}$ & ++ & ++ & ++ & \\
\hline $7 \mathrm{~h}$ & & & ++ & \\
\hline $9 h$ & +++ & +++ & +++ & \\
\hline
\end{tabular}

11) congestão do baço, leve congestão nos rins (8/11), leve congestão pulmonar $(3 / 11)$, leve congestão hepática $(1 / 11)$, de leve a moderada vacuolização difusa das células hepáticas (2/11).

Testes com papel picro-sódico

Os dados sobre o teste do papel picro-sódico com as três plantas constam nos Quadros 7 a 9.

\section{DISCUSSÃO E CONCLUSÕES}

A dose letal para Piptadenia. macrocarpa para coelhos foi $6 \mathrm{~g} /$ $\mathrm{kg}$ para a brotação dessecada, coletada até 5 meses antes dos experimentos; 6 meses após a coleta, a planta tinha perdido a sua toxidez. A dose letal para $P$. viridiflora para coelhos também foi $6 \mathrm{~g} / \mathrm{kg}$ para a brotação dessecada, coletada dois meses antes dos experimentos; 12 meses após a coleta, a planta tinha metade da toxidez. Já para Holocalxy glaziovii a dose letal foi 0,75 a $1,5 \mathrm{~g} / \mathrm{kg}$ para a folha dessecada, coletada um mês e meio antes dos experimentos, moída logo e armazenada em vidros com tampa plástica e guardada à temperatura ambiente, com perda aproximada de metade da toxidez no prazo de um ano ( $1^{\text {a }}$ série). A segunda série de experimentos, realizada com a folha dessecada armazenada em sacos de algodão e só moída por ocasião da realização dos experimentos, indica que há uma leve melhor conservação da toxidez da planta quando moída logo e conservada em vidros com tampa plástica.

Pelos dados obtidos, pode-se concluir que o coelho é sensível à intoxicação pelas folhas de Piptadenia macrocarpa, Piptadenia viridiflora e Holocalyx glaziovii, podendo portanto ser usado em trabalhos complementares futuros sobre a toxidez dessas plantas. As folhas dessecadas dessas plantas mantém-se tóxicas durante alguns meses ( $P$. macrocarpa), ou pelo menos um ano (P.viridiflora e $H$. glaziovii), nesse último caso porém perdem neste período aproximadamente a metade de sua toxidez. As folhas de H. glaziovii moídas logo 
Quadro 9. Reações ao teste do papel picro-sódico das folhas dessecadas de Holocalyx glaziovii

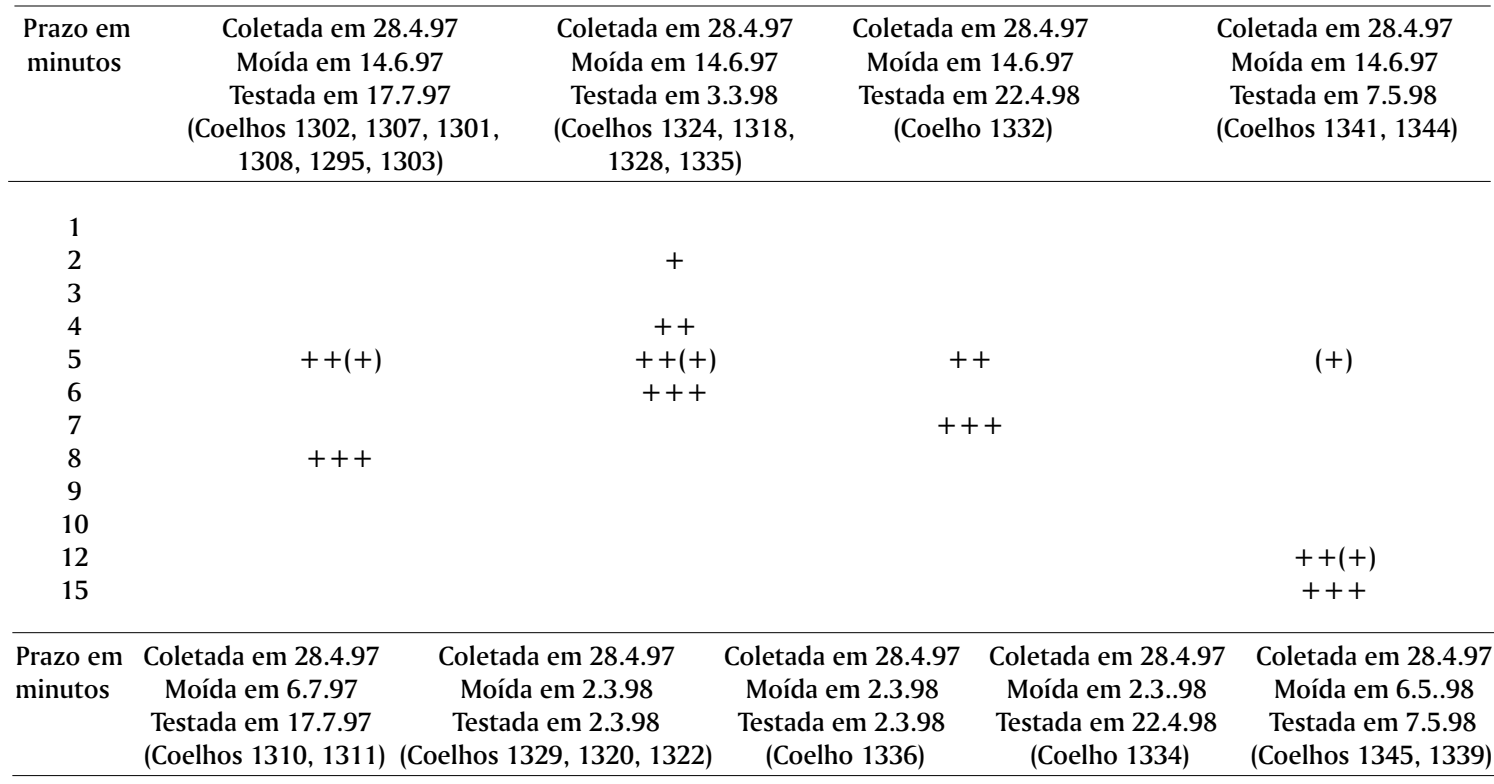

$\begin{array}{ccc} & + & \\ & +(+) & + \\ & +(+) & \\ ++ & ++ & +(+) \\ & ++(+) & ++ \\ & +++ & ++(+) \\ ++ & & +++\end{array}$

++
$++(+)$

$+++$
$(+)$

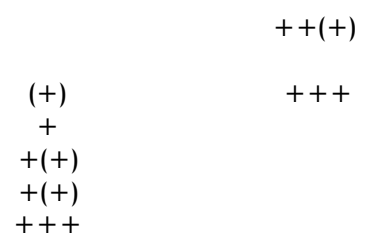

\section{REFERÊNCIAS}

Döbereiner J., Rezende, A.M.L. \& Tokarnia C.H. 1976. Intoxicação experimental por Baccharis coridifolia em coelhos. Pesq. Agropec. Bras., Sér. Vet. 11:2735.

Tokarnia C.H., Döbereiner J. \& Peixoto P.V. 1994. Aspectos clínico-patológicos complementares da intoxicação por algumas plantas tóxicas brasileiras. Pesq. Vet. Bras. 14(4):111-122.

Tokarnia C.H, Peixoto P.V., Brito M.F., Duarte M.D. \& Brust L.A.G. 1999. Estudos experimentais com plantas cianogênicas em bovinos. Pesq. Vet. Bras. 19(2):84-90. 